\title{
Needs for Small Area Estimation: Perspectives From the US Private Forest Sector
}

\author{
Steve Prisley ${ }^{1 *}$, Jeff Bradley², Mike Clutter ${ }^{3}$, Suzy Friedman ${ }^{4}$, Dick Kempka ${ }^{5}$, \\ Jim Rakestraw ${ }^{6}$ and Edie Sonne Hall ${ }^{7}$ \\ ${ }^{1}$ National Council for Air and Stream Improvement, Roanoke, VA, United States, ${ }^{2}$ American Forest \& Paper Association, \\ Washington, DC, United States, ${ }^{3}$ Forest Investment Associates, Atlanta, GA, United States, ${ }^{4}$ National Alliance of Forest \\ Owners, Washington, DC, United States, ${ }^{5}$ Molpus Woodlands Group, LLC, Jackson, MS, United States, ${ }^{6}$ International \\ Paper, Statesboro, GA, United States, ${ }^{7}$ Three Trees Consulting, Seattle, WA, United States
}

\section{OPEN ACCESS}

Edited by:

Aaron Weiskittel,

University of Maine, United States

Reviewed by: John Paul McTague,

University of Georgia, United States

Roque Rodríguez-Soalleiro,

University of Santiago

de Compostela, Spain

Ben Rice,

Midgard Natural Resources,

United States

*Correspondence:

Steve Prisley

sprisley@ncasi.org

Specialty section:

This article was submitted to

Forest Management,

a section of the journal

Frontiers in Forests and Global

Change

Received: 23 July 2021

Accepted: 20 October 2021

Published: 11 November 2021

Citation:

Prisley S, Bradley J, Clutter M,

Friedman S, Kempka D, Rakestraw J and Sonne Hall E (2021) Needs for Small Area Estimation: Perspectives From the US Private Forest Sector.

Front. For. Glob. Change 4:746439.

doi: 10.3389/ffgc.2021.746439
The commercial forest sector in the US includes forest landowners and forest products manufacturers, as well as numerous service providers along the supply chain. Landowners (and contractors working for them) manage forestland in part for roundwood production, and manufacturers purchase roundwood as raw material for forest products including building products, paper products, wood pellets, and others. Both types of organizations need forest resource data for applications such as strategic planning, support for certification of sustainable forestry, analysis of timber supply, and assessment of forest carbon, biodiversity, or other ecosystem services. The geographic areas of interest vary widely but typically focus upon ownership blocks or manufacturing facilities and are frequently small enough that estimates from national forest inventory data have insufficient precision. Small area estimation (SAE) has proven potential to combine field data from the national forest inventory with abundant sources of remotely sensed or other resource data to provide needed information with improved precision. Successful implementation of SAE by this sector will require cooperation and collaboration among federal and state government agencies and academic institutions and will require increased funding to improve data collection, data accessibility, and further develop and implement the needed technologies.

Keywords: landowner, manufacturer, sustainability, markets, carbon, precision

\section{INTRODUCTION}

Our purpose here is to articulate the needs of the US private forest sector for enhanced forest resource information that might be possible through the application of small area estimation (SAE), combining plot data from the national forest inventory with supplemental data from remote sensing or other geospatial sources. We use the term "small area estimation" to refer to a suite of statistical approaches to improve the precision of forest inventory estimates for small geographic areas or categories by incorporating additional data beyond the plot measurements themselves.

The private forest sector is a dominant contributor to many aspects of forestry in the US. In this article, we use the term "private forest sector" to include manufacturers of forest products and private timberland owners. The term "working forests" has been used widely to refer to forests that 
are managed to provide a steady supply of wood to forest products markets while providing other ecosystem benefits. However, there are no publicly available data that can distinguish forest areas based on management intent of private owners. We therefore use the term "private timberlands" as the closest approximation to "working forests." We adopt the definition of "timberland" from the national forest inventory, which defines it as forest land capable of producing at least 20 cubic feet of wood per acre per year and not reserved from harvest.

Private timberland owners (organizations and families) own nearly $60 \%$ of forest land, provide nearly $90 \%$ of wood harvested for products, and account for more than $80 \%$ of forest volume growth (Oswalt et al., 2019). Forest products manufacturers account for approximately four percent of the total US manufacturing GDP, produce nearly $\$ 300$ billion in products annually and employ approximately 1 million people. The industry meets a payroll of approximately $\$ 60$ billion annually and is among the top 10 manufacturing sector employers in 45 states.

The private forest sector is also a primary contributor to natural climate solutions. Private timberlands store more than half of the forest carbon in the US, and account for nearly $75 \%$ of annual gross sequestration. Sustainable harvest of wood for products has led to increasing forest carbon stocks and increasing carbon storage in harvested wood products. Numerous studies confirm that active markets for wood provide an incentive for landowners to maintain or increase forest area and productivity (Lubowski et al., 2008; Abt et al., 2010, 2014; Costanza et al., 2016; Dale et al., 2017; Jefferies and Leslie, 2017; Birdsey et al., 2018; Kim et al., 2018).

The private sector is an extensive user of information from the national forest inventory, housed in the Forest Inventory and Analysis (FIA) program of US Forest Service Research. The FIA program conducts annual field inventory across all ownerships in the US, as well as surveys on mill production (through the Timber Product Output program) and forest owners (through the National Woodland Owner Survey). The field inventory is conducted on permanent plots across all ownerships at a sampling intensity of one plot per 2,400 hectares $(5,937$ acres). A subset of plots in all states is remeasured annually such that all plots in the eastern US are remeasured every 5-7 years, and plots in the west are remeasured every 10 years.

National forest inventory data is also widely used by carbon credit programs to assess baseline forest carbon levels. For example, the California Cap and Trade Program, the largest carbon market for private investors and companies in the US, uses FIA data to determine forest carbon project baselines and the associated volume of credits generated each year. The Family Forest Carbon Program ${ }^{1}$ of the American Forest Foundation and The Nature Conservancy also uses FIA data to establish baseline carbon levels and to measure the performance of forest management practices.

Many users of FIA data have expressed expanding needs for more detailed information on smaller spatial domains

\footnotetext{
${ }^{1}$ www.forestfoundation.org/family-forest-carbon-program
}

while maintaining the core field measurement program (Guldin, 2020a,b). The FIA program has responded with increased research activity in SAE (for example, Brooks et al., 2016; Nagle et al., 2019; Green et al., 2020; Coulston et al., 2021). These efforts have shown that precision can be improved using SAE with plot data combined with ancillary data. While such studies have demonstrated the promise of SAE, none have led to operational production of national datasets.

While FIA is budget-constrained and is currently challenged to maintain even the present level of sample intensity (geographically and temporally), there are abundant remote sensing and geospatial data that could lend increased precision to inventory-based estimates of forest resources. Many of these ancillary data layers and sources may already be used by organizations in the forest sector: soils data, satellite and aerial imagery, canopy heights from LIDAR or aerial photogrammetry, topography, hydrography, land cover, and numerous others. The pressing needs of the private sector for higher-precision resource information argue for further research in SAE methods and delivery of tools to apply these methods.

In the following sections, we will first provide examples of reasons why the private forest sector is facing increasing needs for reliable forest resource information. Then we discuss the specific estimates from FIA data that can meet these needs, with examples of current levels of precision of these estimates. Finally, we highlight opportunities for improvements that would enhance the value of FIA data for the private forest sector as well as many other users.

\section{EXAMPLES OF WHY INFORMATION IS NEEDED}

\section{Assessment of Forest and Carbon Sustainability}

Sustainability certification and reporting are critical for forest sector companies to document their performance against sustainability standards. Forest sector organizations are increasingly investing time and effort in reporting Environmental, Social, and Governance (ESG) indicators to communicate to customers and investors that sustainability is embedded in their business practices.

For manufacturers certifying the sustainability of their supply chain, this reporting leads to an increased need for resource data from the geographic regions in which they operate, which is often met using data from FIA. For example, both the Sustainable Forestry Initiative (SFI) and Forest Stewardship Council (FSC) certification standards include requirements that companies avoid the use of wood that may come from forests that have been converted to non-forest use (deforestation). This requires regular monitoring of forest land use changes within operating regions. Unfortunately, FIA-based estimates of forest area change for smaller regions (e.g., small states or woodbaskets) may fail to reach 
precision targets defined by certification standards, such as demonstrating with statistical significance that forest area is not declining.

For private timberland owners with detailed data on their own holdings, FIA data may be used to obtain factors for tree species in a region to convert inventory volumes to carbon stocks, and to estimate carbon in pools other than live trees. Furthermore, trade associations representing segments of the forest sector make extensive use of FIA data to communicate the sustainability of forests and their contributions to meeting environmental goals.

Other certification requirements involve attention to the quantity of wood harvested relative to the quantity grown. Such growth/drain analyses are common, but require estimates of change over time. Because harvest is a relatively rare event across large landscapes, the sample size for estimates of harvest are small, leading to higher uncertainties. Demonstrating that growth exceeds removals with statistical significance is often difficult for some areas using FIA plot data alone.

New guidelines are being developed for companies to report on value chain effects of their products on terrestrial carbon dynamics. One proposed metric involves carbon stock changes on lands from which they obtain raw materials. In a forestry context, this would require carbon stock estimates at a regional or woodshed level from two successive inventories and expressing that stock change relative to the quantity of wood harvested. Without employing SAE approaches, such estimates have high uncertainties.

\section{Wood Markets}

Landowners and manufacturers are engaged in markets for roundwood from forests, as sellers and buyers, respectively. For both, it is essential to understand the market dynamics in their operating regions to plan effectively. This entails knowing the relationship between forest area change, forest growth, mortality, and harvest within a geographic area. These dynamics are critical to evaluating long-term resource availability and sustainability.

Land use change is a longer-term driver of wood markets and can affect the availability and cost of wood in rapidly developing areas. Similarly, economic disruptions to local wood markets can occur when established mills cease or reduce operations, or when new mills begin operations. Catastrophic events such as fire, hurricanes, or drought can quickly and dramatically alter local resource availability. Therefore, companies must monitor wood market conditions within their operating areas, requiring information on harvest levels, mortality, land ownership changes, forest area changes, and forest growth rates.

\section{Forest Carbon Markets}

The potential for forests in the US to contribute to natural climate solutions has spawned interest and activity in forest carbon offset markets. Such markets are designed to incentivize forest owners to increase average forest carbon stocks through payments for carbon offsets. To produce real climate benefits, forest carbon offset markets need to account for (a) carbon stored in products as well as forests, (b) additionality (benefits above and beyond business-as-usual behavior), (c) leakage (emissions that occur due to increased harvests outside a project that compensate for reduced harvests within a project), and (d) substitution (higher emissions resulting from the use of carbon-intensive substitute products such as concrete or steel in place of wood-based building products). Addressing these considerations requires data on initial forest carbon stocks for project areas, forest growth rates, levels of harvest associated with a "business-asusual" or "standard practice" baseline, eventual use of harvested wood within the region (proportion of harvest going to lumber, panels, paper, fuel, etc.), and market factors related to leakage and substitution (such as supply and demand elasticities). National forest inventory data can meet some of these information needs for large areas, but some estimates will lack needed precision for smaller geographic areas.

\section{Biodiversity at Landscape Scale}

Private timberland owners and manufacturers recognize the importance of conducting forest management activities in a way that conserves habitat for species of conservation concern. A first step in doing so is understanding the geographic distribution of forest conditions associated with individual species.

Forest inventory data can be used to assess the relative quality of habitat for some species by quantifying relevant aspects of stand structure. For example, in a protocol developed to assess quality of open-canopy pine forests for species of concern in the US South (Nordman et al., 2016), metrics include proportion of basal area in pine trees (of certain species) in specified diameter ranges, proportion of basal area in hardwood trees, percent canopy cover from pine species, and stand density index. Similarly, Davis et al. (2015) describe an old-growth structure index (OGSI) for the Pacific Northwest derived from inventory metrics such as density of live trees above a diameter threshold, density of standing dead trees above a diameter threshold, percent cover by down dead wood of certain size, and an index of tree diameter diversity.

While protocols and indices such as these can be applied to FIA data and be extremely useful in broad-scale monitoring of structural diversity at a landscape scale, the categorical domains can be very narrow (e.g., trees per hectare greater than $100 \mathrm{~cm}$ diameter). Obtaining estimates of uncertainty for indices involving multiple metrics can quickly become intractable, and uncertainties will almost certainly be high even across large geographical areas. Davis et al. (2015) noted sources of uncertainties but were not able to quantify general levels of uncertainty in results.

If suitable ancillary data are available (from FIA or other publicly accessible sources) to lend strength to some of the estimates needed for these indices, then SAE approaches may prove valuable in quantifying uncertainties and improving precision of estimates related to biodiversity.

\section{TYPE OF FOREST RESOURCES DATA NEEDED}

Clearly, the forest sector needs current, reliable data on the forest resources they manage or depend on for raw materials. 
Data needs include forest area and change over time, estimates of relevant resource quantities (e.g., wood volume, biomass, carbon) and the current rates of change of those quantities. These rates of change include categories such as forest growth, mortality, and harvest. Information regarding the geographic distribution of resources is important, especially as it relates to transportation networks, manufacturing facilities, population centers, and features that affect management practices, such as steep slopes, soil erodibility, wetlands, and habitat for species of conservation concern.

Typically, resource information needs are limited geographically to the operating regions for individual organizations. For timberland owners, it would be the areas in and around their forest holdings. For manufacturers, it would be areas within a sourcing region for each of their facilities. These regions are often small enough that there are insufficient numbers of FIA samples to provide inventory-based estimates with reasonable precision in categories of interest.

To illustrate the levels of uncertainty of commonly used estimates available from FIA plot data for typical operating areas, we developed estimates for an $80 \mathrm{~km} \mathrm{(50} \mathrm{mile)} \mathrm{and}$ $160 \mathrm{~km}$ (100 mile) radius around an arbitrary location in the US South near the Georgia-Alabama border (Table 1). In this example, we consider either a landowner or a manufacturer interested in softwood sawtimber available from private timberlands in the operating area. Therefore, relevant information would include area in pine forest types, pine forest area by age class (for modeling future supplies), softwood sawtimber growing stock volumes, and growth and removals of softwood sawtimber. For all variables, we retrieved summary information using the USFS EVALIDator tool (USDA Forest Service, 2021) accessing 2019 inventories for Georgia and Alabama.

Ninety-percent confidence intervals on softwood sawtimber volumes on private lands are $\pm 12.7 \%$ and $\pm 6.6 \%$ for the 80 and $160 \mathrm{~km}$ radius areas, respectively. Note that the sample size for harvest removals is only $23-25 \%$ of the sample size for private pine timberland area. Samples with harvests represent plots on which harvest occurred at some point during a 57 year period between plot measurements. This relative rarity of harvest activity leads to far greater uncertainty in estimates: $90 \%$ confidence intervals for annual harvest removals are \pm 29.3 and $\pm 16.9 \%$ for the 80 and $160 \mathrm{~km}$ radius areas, respectively.

\section{DISCUSSION}

\section{Precision Targets}

If confidence intervals for needed estimates (Table 1) are considered low or inadequate, it is reasonable to ask what levels of precision for specific estimates are needed? Is there a threshold at which a confidence interval would be deemed "acceptable"? Unfortunately, it is extremely difficult in most cases to specify a target confidence interval that is needed. Resource information from inventory data is just one factor among many that affect private sector decisions. Managers frequently face decisions involving financial variables such as taxes and interest rates, market variables such as anticipated demand and supply, international and regional competition for raw materials, and restrictions on other key resources. Few, if any, of these factors carry estimates of uncertainty, so it is unlikely managers could specify a threshold for needed precision of resource data. Furthermore, decisions frequently must be made within a limited time; there is little room to wait for "better information" before deciding. Often, the best that can be done is to put estimated levels of uncertainty into context with other decision variables and consider risks related to uncertainty.

A possible exception is when statements about rates of change must be made with some level of confidence. For example, it may be important for certification or reporting purposes to be able to state that forest area or forest carbon stocks are not decreasing within an operating area. This implies that measured change in forest area or carbon stocks can be shown to be increasing or stable (changing at a rate not significantly different from zero), with a specified confidence. In such cases, though, the precision

TABLE 1 | Example of variables of interest, sample size, and 90\% confidence interval for FIA plot-based estimates for 80 and $160 \mathrm{~km}$ radii around an arbitrary location.

\begin{tabular}{|c|c|c|c|c|c|c|}
\hline \multirow[t]{2}{*}{ Variables of interest } & \multicolumn{3}{|c|}{$80 \mathrm{~km}$ radius } & \multicolumn{3}{|c|}{$160 \mathrm{~km}$ radius } \\
\hline & Estimate & $\begin{array}{l}\text { Sample size } \\
\text { (plots) }\end{array}$ & $\begin{array}{c}\text { Conf. interval } \\
(\%)\end{array}$ & Estimate & $\begin{array}{l}\text { Sample size } \\
\text { (plots) }\end{array}$ & $\begin{array}{c}\text { Conf. interval } \\
(\%)\end{array}$ \\
\hline Area of private timberland (ha) & $1,347,355$ & 629 & 6.2 & $4,943,146$ & 2,317 & 2.5 \\
\hline Area in pine forest types (ha) & 657,714 & 346 & 9.0 & $2,236,049$ & 1,188 & 2.5 \\
\hline \multicolumn{7}{|l|}{ Pine forest area by age class (ha) ${ }^{a}$} \\
\hline $0-5$ years & 48,962 & 25 & 34.5 & 208,381 & 112 & 16.5 \\
\hline $6-10$ years & 66,524 & 33 & 29.7 & 210,478 & 118 & 16.4 \\
\hline $11-15$ years & 53,468 & 29 & 33.2 & 241,033 & 133 & 15.3 \\
\hline Softwood sawtimber volume $\left(\mathrm{k} \mathrm{m}^{3}\right)$ & 58,983 & 283 & 12.7 & 171,898 & 914 & 6.6 \\
\hline Annual softwood sawtimber growth ( $\left.\mathrm{k} \mathrm{m}^{3} / \mathrm{yr}\right)$ & 4,517 & 302 & 12.3 & 13,764 & 987 & 6.4 \\
\hline Annual softwood sawtimber harvest ( $\left.\mathrm{k} \mathrm{m}^{3} / \mathrm{yr}\right)$ & 1,481 & 87 & 29.3 & 4,441 & 273 & 16.9 \\
\hline
\end{tabular}

All estimates pertain to private timberland only.

a Only three age classes listed for brevity. 
target will depend on the underlying rate of resource change, so it will differ in different geographic areas.

\section{Privacy Concerns}

The US private forestry sector has valued privacy of information and regulations that protect confidentiality of business information. Therefore, some might expect concerns within the private sector about public access to fine-grain resource information developed through SAE. However, this issue was never raised in an FIA User Group meeting on SAE attended by 74 participants, including representatives of private timberland owners (Guldin, 2020b). Furthermore, several of the authors of this manuscript work for private timberland owners or associations, and none have expressed such concerns. With widespread public access to high-resolution imagery, public records of land ownership, and numerous interpretive maps such as forest biomass distribution, it is clear that the risk of loss of privacy is outweighed by the gains possible through broader adoption of SAE applied to forest resource data.

\section{Moving Forward}

The FIA program is the logical place for expanding research and development of SAE applied to forest resource data. However, meeting the private sector resource information needs will require partnership, concerted effort, and increased investment.

The private sector is already partnering with the FIA program in a variety of ways: cooperative funding of research into SAE, cooperating with FIA by allowing access to private lands for field inventory, and responding to Timber Products Output and National Woodland Owner Survey questionnaires. The private sector also has been a strong supporter of the FIA program by advocating for increased funding for the program. The FIA program, in turn, has proven responsive to needs expressed by the private sector through Blue Ribbon Panels on FIA and annual FIA user group meetings.

There are several opportunities that could benefit not only the private forest sector, but many public and academic users of FIA data as well. These may be categorized as improving the quality and consistency of data, making data more accessible to users, and making better use of technology and ancillary datasets.

Improving the quality and consistency of data:

- Organizations within the private sector may be able to help FIA validate research products using proprietary resource data, such as assessment of accuracy of SAE products using fine-scale company inventory data;

- FIA and other units within USFS Research can focus on closing substantial data and knowledge gaps related to belowground and dead wood carbon dynamics, forest management effects on carbon cycles, soil carbon sequestration in forest ecosystems, and storage of carbon in harvested wood products;

- FIA program leadership can work to improve the nationwide consistency of field protocols and analytical approaches that will ensure credible, consistent, and timely data on forest carbon stocks and fluxes.
Making data more accessible to users:

- The FIA program could benefit from external expertise to improve the design and delivery of online tools for analysis and dissemination of data to significantly enhance accessibility and usability;

- Early engagement with the user community in the design of tools for delivery of SAE estimates would help ensure that resulting products meet user needs.

Making better use of technology and ancillary datasets:

- Because land use change is such a critical factor in forest carbon fluxes, FIA can build on successes using remote sensing-based programs such as the Landscape Change Monitoring System (LCMS) and Image-based Change Estimation (ICE) to arrive at a reliable, annually updated source of information on nationwide forest area change;

- FIA scientists can move from a research to an implementation phase for SAE applications to national forest inventory data, which will require deciding on specific ancillary datasets (such as remote sensing products) and methods that show the greatest promise.

Improvement of resource data delivery with SAE builds on the foundation of the FIA phase 2 field inventory. None of the advances recommended here should come at the expense of the core program of field inventory. This means that advances are dependent on additional funding. At every opportunity, private sector organizations should advocate for full and increased funding for the FIA program to meet these objectives.

\section{SUMMARY}

The US forest sector is highly dependent on the contributions made by private timberland owners and manufacturers. Private sector stakeholders are facing increasing demands for resource information, which could be met in part by data from the national forest inventory. Improved precision in estimates from FIA can be achieved using SAE approaches and leveraging additional datasets. Additional federal investment in research, aided by partnership efforts with the private sector, states, and educational institutions will be necessary to meet private sector information needs.

\section{DATA AVAILABILITY STATEMENT}

The original contributions presented in the study are included in the article/supplementary material, further inquiries can be directed to the corresponding author.

\section{AUTHOR CONTRIBUTIONS}

SP developed the initial draft. JB, MC, SF, DK, JR, and ES participated equally in review and revision. All authors contributed to the article and approved the submitted version. 


\section{REFERENCES}

Abt, K. L., Abt, R. C., Galik, C. S., and Skog, K. E. (2014). Effects of Policies on Pellet Production and Forests in the U.S. South: A Technical Document Supporting the Forest Service 2010 RPA Assessment. General Technical Report SRS202. Asheville, NC: United States Department of Agriculture Forest Service, Southern Research Station.

Abt, R. C., Galik, C. S., and Henderson, J. D. (2010). The Near-Term Market and Greenhouse Gas Implications of Forest Biomass Utilization in the Southeastern United States. Durham, NC: Duke University, Nicholas Institute for Environmental Policy Solutions and Center on Global Change.

Birdsey, R., Duffy, P., Smyth, C., Kurz, W. A., Dugan, A. J., and Houghton, R. (2018). Climate, economic, and environmental impacts of producing wood for bioenergy. Environ. Res. Lett. 13:050201.

Brooks, E. B., Coulston, J. W., Wynne, R. H., and Thomas, V. A. (2016). Improving the precision of dynamic forest parameter estimates using Landsat. Rem. Sens. Environ. 179, 162-169.

Costanza, J. K., Abt, R. C., McKerrow, A. J., and Collazo, J. A. (2016). Bioenergy production and forest landscape change in the southeastern U.S. Glob. Change Biol. Bioenergy 9, 924-939.

Coulston, J. W., Green, P. C., Radtke, P. J., Prisley, S. P., Brooks, E. B., Thomas, V. A., et al. (2021). Enhancing the precision of broad-scale forestland removals estimates with small area estimation techniques. For. Int. J. For. Res. 94, 427-441.

Dale, V. H., Parish, E., Kline, K. L., and Tobin, E. (2017). How is woodbased pellet production affecting forest conditions in the southeastern United States? For. Ecol. Manage. 396, 143-149. doi: 10.1016/j.foreco.2017. 03.022

Davis, R. J., Janet, O. L., Robert, K. E., Warren, C. B., Matthew, G. J., Zhiqiang, Y., et al. (2015). Northwest Forest Plan-the first 20 years (1994-2013): Status and Trends of Late-Successional and Old-Growth Forests. Gen. Tech. Rep. PNW-GTR-911. Portland, OR: U.S. Department of Agriculture, Forest Service, Pacific Northwest Research Station, 112.

Green, P. C., Burkhart, H. E., Coulston, J. W., Radtke, P. J., and Thomas, V. A. (2020). Auxiliary information resolution effects on small area estimation in plantation forest inventory. For. Int. J. For. Res. 93, 685-693. doi: 10.1093/ forestry/cpaa012

Guldin, R.W., ed. (2020a). Program Summary: Forest Inventory and Analysis Program National Users Group Meeting. August 17-21, 2020. Washington, DC: Society of American Foresters, 27.

Guldin, R.W., ed. (2020b). Program Summary: Small Area Estimation Focus Sessions at Forest Inventory and Analysis Program National Users Group Meeting. September 30 - October 2, 2020. Washington, DC: Society of American Foresters, 21.
Jefferies, H. M., and Leslie, T. (2017). Historical Perspective on the Relationship Between Demand and Forest Productivity in the US South. Charlotte, NC: Forest2Market, Inc, 104.

Kim, T. J., Wear, D. N., Coulston, J., and Li, R. (2018). Forest land use responses to wood product markets. For. Policy Econ. 93, 45-52. doi: 10.1016/j.forpol.2018. 05.012

Lubowski, R. N., Plantinga, A. J., and Stavins, R. N. (2008). What drives land-use change in the United States? A national analysis of landowner decisions. Land Econ. 84, 529-550. doi: 10.3368/le.84.4.529

Nagle, N. N., Schroeder, T. A., and Rose, B. (2019). A regularized raking estimator for small-area mapping from forest inventory surveys. Forests 10, 1-17. doi: 10.3390/F10111045

Nordman, C., White, R., Wilson, R., Ware, C., Rideout, C., Pyne, M., et al. (2016). Rapid Assessment Metrics to Enhance Wildlife Habitat and Biodiversity Within Southern Open Pine Ecosystems, version 1.0. March 31, 2016. Durham, NC: U.S. Fish and Wildlife Service and NatureServe, for the Gulf Coastal Plains and Ozarks Landscape Conservation Cooperative.

Oswalt, S. N., Brad, S. W., Patrick, M. D., and Scott, P. A. (2019). Forest Resources of the United States, 2017: a technical document supporting the Forest Service 2020 RPA Assessment. Gen. Tech. Rep. WO-97. Washington, DC: U.S. Department of Agriculture, Forest Service, Washington Office, 223. doi: 10.2737/WO-GTR-97 USDA Forest Service (2021). Forest Inventory EVALIDator Web-Application Version 1.8.0.01. Forest Inventory and Analysis Program. St. Paul, MN: U.S. Department of Agriculture, Forest Service, Northern Research Station.

Conflict of Interest: SP was employed by the National Council for Air and Stream Improvement, Inc.; JB was employed by the American Forest \& Paper Association; MC was employed by Forest Investment Associates; SF was employed by the National Alliance of Forest Owners; DK was employed by Molpus Woodlands Group, LLC; JR was employed by International Paper; and ES was a principal at Three Trees Consulting.

Publisher's Note: All claims expressed in this article are solely those of the authors and do not necessarily represent those of their affiliated organizations, or those of the publisher, the editors and the reviewers. Any product that may be evaluated in this article, or claim that may be made by its manufacturer, is not guaranteed or endorsed by the publisher.

Copyright (c) 2021 Prisley, Bradley, Clutter, Friedman, Kempka, Rakestraw and Sonne Hall. This is an open-access article distributed under the terms of the Creative Commons Attribution License (CC BY). The use, distribution or reproduction in other forums is permitted, provided the original author(s) and the copyright owner(s) are credited and that the original publication in this journal is cited, in accordance with accepted academic practice. No use, distribution or reproduction is permitted which does not comply with these terms. 